\title{
Squamous Cell Carcinoma of Kidney Associated with Hydronephrosis and Multiple Renal Calculi - A Rare Case Report
}

Dr. Vijaya Lakshmi Muram Reddy ${ }^{1 *}$, Dr. Penchala Reddy Muram Reddy ${ }^{2}$, Dr. Shanthi Vissa ${ }^{3}$, Dr. Mohan Rao Nandam ${ }^{4}$ Dr. Syam Sundara Rao Byna ${ }^{5}$, Dr. Bhavana Grandhi ${ }^{6}$, Dr. Venkata Sunanda Lakshmi Gelli ${ }^{7}$

\footnotetext{
${ }^{1,2,6}$ Associate Professor, Department of pathology Narayana Medical College and Hospital, Nellore, Andhrapradesh, India

${ }^{3,4,5}$ Professor, Department of Pathology Narayana Medical College and Hospital Nellore, Andhrapradesh, India

${ }^{7}$ Assistant Professor, Department of Pathology Narayana Medical College and Hospital Nellore, Andhrapradesh, India
}

DOI: $\underline{10.36348 / \text { sjpm.2019.v04i11.007 }}$

| Received: 11.11.2019| Accepted: 18.11.2019| Published: 24.11.2019

*Corresponding author: Dr. Vijaya Lakshmi Muram reddy

\section{Abstract}

Squamous cell carcinoma of kidney is extremely rare tumor and the incidence is less than $1 \%$ of all renal malignancies. In the world literature till now, very few cases of primary squamous cell carcinoma of kidney have been reported. Squamous cell carcinoma is frequently associated with renal calculi and hydronephrosis. Squamous cell carcinoma of kidney is very aggressive, presents at an advanced stage and is associated with poor prognosis. Here, we report a case of squamous cell carcinoma diagnosed in hydronephrotic kidney with multiple renal calculi in a 60 year old male patient. Patients presenting with long standing history of renal calculus and associated hydronephrosis should undergo extensive diagnostic workup for the early diagnosis of squamous cell carcinoma, so that we can reduce the morbidity and mortality. Keywords: Squamous cell carcinoma, Hydronephrosis, Renal calculi, Kidney.

Copyright @ 2019: This is an open-access article distributed under the terms of the Creative Commons Attribution license which permits unrestricted use, distribution, and reproduction in any medium for non-commercial use (NonCommercial, or CC-BY-NC) provided the original author and sources are credited.

\section{INTRODUCTION}

Squamous cell carcinoma of kidney is very rare neoplasm and the incidence is less than $1 \%$ of all renal malignancies. Squamous cell carcinoma is more commonly reported in urinary bladder and urethra rather than in the kidney [1]. In the world literature till now, very few cases of primary squamous cell carcinoma of kidney have been reported [2]. This tumor is very aggressive, high grade and presents at an advanced stage. Thus it has poor prognosis [1,3]. Squamous cell carcinoma is frequently associated with renal calculi and hydronephrosis[4]. Here, we report a case of squamous cell carcinoma of kidney in a 60 year old male, diagnosed on histopathological examination; which has been clinically presented as hydronephrosis with multiple renal calculi.

\section{CASE REPORT}

A 60 year old male presented to the urology outpatient department with history of loin pain since 10 days and swelling in the right hypochondrium since 1 month. He was a chronic smoker and alcoholic since 20 years. Blood urea, serum creatinine and electrolytes levels are normal. Haematological parameters are normal except that haemoglobin value in somewhat low $[12.4 \mathrm{gm} / \mathrm{dl}]$. He was not hypertensive or diabetic.
On ultrasonography, right kidney was enlarged in size showing features of hydronephrosis with free floating echoes noted in right kidney. Two calculi of sizes $58 \mathrm{~mm}$ and $49 \mathrm{~mm}$ were noted in upper and lower calyceal system. Renal cortical thickness and echogenicity are normal and right ureter is dilated. Left kidney was normal. Ultrasound thorax showed bilateral pleural effusion.

CT scan KUB was done and showed enlarged right kidney of size $14 \times 9 \mathrm{~cm}$. Gross hydronephrosis with features of marked dilatation of pelvi calyceal system and parenchymal thinning was noted. A large calculus of size $6 \times 5 \mathrm{~cm}$ was seen occupying the entire renal pelvis, another calculus of size $3 \times 2 \mathrm{cms}$ was noted in mid calyx and calculus of size $3 \times 1 \mathrm{~cm}$ was noted in lower calyx. Multiple solid papillary lesions are seen in the mid and lower calyces of right kidney with calcifications and these features raise the possibility of underlying malignancy. Left kidney was normal.

Under general anaesthesia; the patient underwent right open simple nephrectomy. The biopsy specimen was fixed in $10 \%$ formalin and was sent for histopathological examination. 
On gross examination, the right kidney was found to be enlarged in size measuring $12 \times 8 \times 6 \mathrm{~cm}$ and ureter length measuring $5 \mathrm{cms}$.External surface of kidney was covered by perinephric pad of fat. It was grey brown to grey white in colour, nodular, irregular and the capsule was adherent. Cut section shows dilatation of pelvicalyceal system and there is loss of corticomedullary differentiation. Grey white nodular thickened areas are seen and in few areas cortex is atrophied. Necrotic material is also seen (Figure 1).One large calculi of size $3 \times 2 \mathrm{cms}$ was noted in the pelvis, other two calculi are noted in upper pole and lower pole of kidney each measuring $2 \times 2 \mathrm{~cm}$.



Fig-1: Cut section of kidney showing grey white nodular thickened areas and necrotic material

Histopathological examination of grey white nodular thickened areas reveal sheets of pleomorphic squamous epithelial cells having round to oval nuclei with prominent nucleoli and with moderate to abundant cytoplasm.Many keratin pearls and atypical mitotic figures are noted (Figure 2). No transitional element was found within the tumor. Adjacent foci shows renal parenchyma, thyroidization of tubules and sclerosed glomeruli (Figure 3). Interstitial stroma shows lymphocytic infiltrate. The histopathological findings were suggestive of well differentiated squamous cell carcinoma arising from the renal pelvis extending into entire renal parenchyma. Resected ends of ureter and renal vessels are free from tumor.There is no lymphovascular invasion. The pathological staging was $\mathrm{PT}_{2 \mathrm{~b}} \mathrm{~N}_{\mathrm{x}} \mathrm{M}_{\mathrm{x}}$. Additional findings of chronic pyelonephritis were also seen.

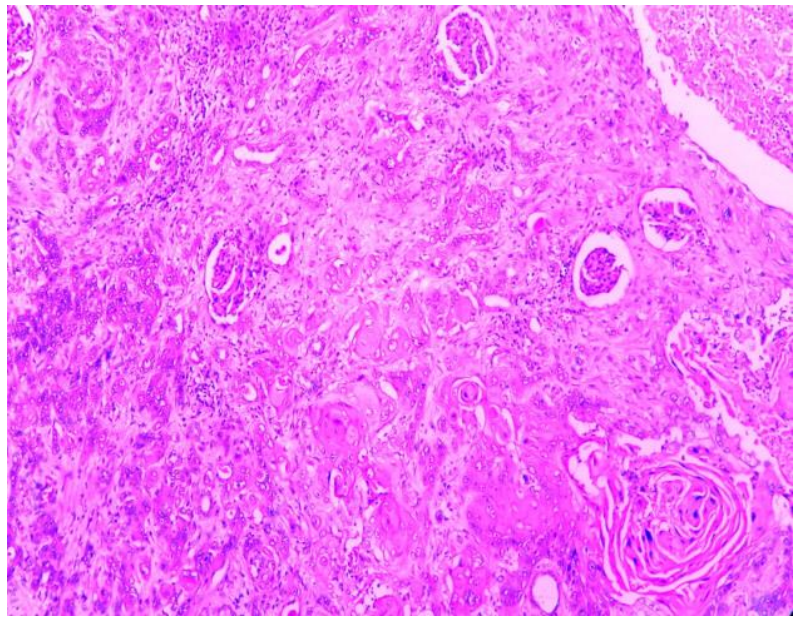

Fig-2: Sheets of pleomorphic squamous cells infiltrating into renal parenchyma

(H\&E,X 100)

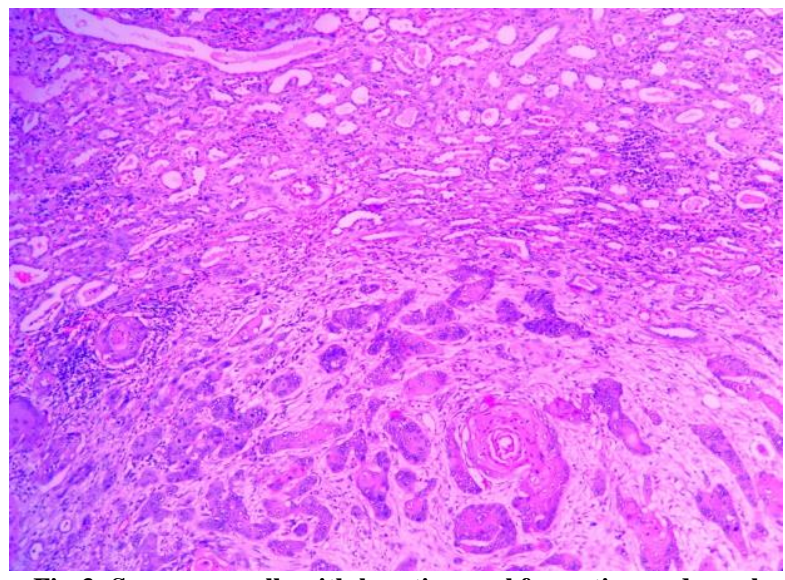

Fig-3: Squamous cells with keratin pearl formation and renal parenchyma showing thyroidization of tubules $(\mathrm{H} \& \mathrm{E}, \mathrm{X100})$

\section{DISCUSSION}

Kidney tumors are usually either adenocarcinoma arising from the renal parenchyma or transitional cell carcinoma arising from the renal pelvis. Squamous cell carcinoma arising from the kidney is a rare entity [5]. Risk factors for squamous cell carcinoma are mainly renal calculi, infection, endogenous and exogenous chemicals, vitamin A deficiency, harmonal imbalance and schistosomiasis [6]. Other risk factors are chronic phenacetin and other analgesics consumption, pyelonephritis, radiation therapy and previous history of renal calculus surgery $[1,4]$.

Smoking and tobacco chewing are the predisposing factors for squamous cell carcinoma of kidney. In our case, the patient is smoker and also alcoholic since 20 years. Squamous cell carcinoma is commonly associated with renal calculi and hydronephrosis [7, 8]. Pyonephrosis with peritoneal abscess formation have also been associated with upper urinary tract carcinomas [2].Chronic irritation because of renal calculi along with inflammation and infection induce squamous metaplasia of the renal collecting 
system that may progress to dysplasia and carcinoma. The important past medical history include repeated episodes of pyelonephritis and nephrolithiasis [3]. Li MK et al. reported coexistence of renal stone in $100 \%$ of cases [8]. Staghorn calculi are more commonly associated with squamous cell carcinoma of renal pelvis [5]. In our case, we have diagnosed that the tumor has arisen from the chronically inflamed hydronephrotic kidney with long term irritation by multiple renal calculi.

Squamous cell carcinoma is seen equally in both sexes. There is no predilection for laterality .The mean age of presentation is around fifth decade [4]. Most common clinical symptoms are dull aching flank pain and hematuria.The cause for pain is pelvi ureteric junction obstruction and local extension. The cause for hematuria is primary tumor mass or renal calculi. The other symptoms are fever, weightloss and paraneoplastic syndromes [4,9]. In advanced cases, the symptoms will be anorexia, weightloss and lethargy [5].

According to the localisation of tumor as central or peripheral; Lee et al. classified this tumor into two variants. Central renal squamous cell carcinoma has more intraluminal components and frequently associated with lymphnode metastasis, whereas peripheral renal squamous cell carcinoma has marked renal parenchymal thickening and usually it will invade the perirenal fat tissue even before the lymphnode or distant metastasis [10].

$\mathrm{Ng}$ et al. reported hydronephrosis is more common in renal tumors when compared to renal pelvic ones [11]. Presence of necrotic material and keratin debris in the hydronephrotic sac is a common finding in squamous cell carcinoma of kidney [6]. In our case, grossly the hydronephrotic kidney had necrotic material and keratin debris along with nodular renal parenchymal thickening.

The diagnosis of squamous cell carcinoma is exclusively restricted for those tumors showing extensive squamous differentiation. The tumor should be diagnosed as urothelial carcinoma with squamous differentiation if a significant urothelial element including urothelial carcinoma in situ is present [6].

The microscopic features of squamous cell carcinoma are keratin pearl formation, intercellular bridges and keratotic cellular debris. Majority of the cases are moderately and poorly differentiated, except verrucous variant. When compared to transitional cell carcinoma, squamous cell carcinoma is more invasive [2]. Immunohistochemistry for squamous cell carcinoma is positive for AE1/AE3, CK7, vimentin and negative for actin,desmin, S100, synaptophysin, CK20 and CEA[2].
The differential diagnosis of squamous cell carcinoma of renal parenchyma is similar lesion in the renal pelvis. To diagnose it as renal parenchymal squamous cell carcinoma, the renal pelvis should be normal histologically. Second differential diagnosis is metastatic squamous cell carcinoma. By taking detailed clinical history and by performing imaging studies and histopathological examination we can rule out the metastatic squamous cell carcinoma [5].

Insidious onset of disease, lack of any pathognomonic signs and synptoms are the main reasons for the delay in the diagnosis [4]. So that, renal squamous cell carcinoma presents at an advanced stage and has poor prognosis. The 5 year survival rate is less than $10 \%$ [3]. Surgery is the main stay of treatment in patients for not having metastatic disease. Radical Nephroureterectomy with excision of bladder cuff is done. In case of patients with metastatic disease, surgery along with cisplatinum based chemotherapy and palliative radiotherapy is given [4]. In case of metastasis, the median survival rate is around 3.5 months [1].

\section{CONCLUSION}

Squamous cell carcinoma of kidney is extremely rare tumor. It is usually associated with renal stones and clinically it presents as hydronephrosis. Patients presenting with long standing history of renal calculus and associated hydronephrosis should undergo extensive diagnostic workup and biopsy is also advised in these patients as they are more suspectible for developing squamous cell carcinoma associated with renal stone disease. Squamous cell carcinoma of kidney is very aggressive, presents at an advanced stage and is associated with poor prognosis. So early diagnosis is important, thereby we can reduce the morbidity and mortality associated with squamous cell carcinoma of kidney.

\section{REFERENCES}

1. El Hachem, G., Choueiry, C., Al Hajj, Obeid, W., Chamseddine, N. (2017). Renal squamous cell carcinoma: Rare and aggressive variant of renal cancers. Cancer Biol ther oncol, 1(2:6),1-4.

2. Saha, A., Roy, C., Ghosh S.K.(2013). Squamous cell carcinoma kidney in a 29 year old male: A case report with review of literature. Clin cancer Investig J, 2(4),347-349.

3. Kalayci, O. T., Bozdag, Z., Sonmezgoz, F., \& Sahin, N. (2013). Squamous cell carcinoma of the renal pelvis associated with kidney stones: radiologic imaging features with gross and histopathological correlation. Journal of clinical imaging science, 3.

4. Singh, V., Sinha, R. J., Sankhwar, S. N., Mehrotra, B., \& Ahmed, N. (1948). Squamous Cell Carcinoma of the Kidney-Rarity Redefined: Case Series with Review of Literature. J Cancer Sci Ther 2: 082-085. doi: 10.4172/1948-5956.1000028. 
5. Lanjewar, S. M., Bodade, R. M., Bansod, A. N., \& Kulkarni, A. (2016). Primary squamous cell carcinoma of kidney: a case report. International Surgery Journal, 2(1), 82-84.

6. Bandyopadhyay, R., Biswas, S., Nag, D., \& Ghosh, A. K. (2010). Squamous cell carcinoma of the renal pelvis presenting as hydronephrosis. Journal of cancer research and therapeutics, 6(4), 537.

7. Busby, J. E., Brown, G. A., Tamboli, P., Kamat, A. M., Dinney, C. P., Grossman, H. B., \& Matin, S. F. (2006). Upper urinary tract tumors with nontransitional histology: a single-center experience. Urology, 67(3), 518-523.

8. Li, M. K., \& Cheung, W. L. (1987). Squamous cell carcinoma of the renal pelvis. The Journal of urology, 138(2), 269-271.

9. Kumar, S., Tomar, V., Yadav, S. S., Udawat, H., Priyadarshi, S., Vyas, N., \& Agarwal, N. (2016).
Primary squamous cell carcinoma of kidney associated with large calculus in non-functioning kidney: a case report. Urology case reports, 8, 4-6.

10. Lee, T. Y., Ko, S. F., Wan, Y. L., Cheng, Y. F., Yang, B. Y., Huang, D. L., \& Chen, W. J. (1998). Renal squamous cell carcinoma: CT findings and clinical significance. Abdominal imaging, 23(2), 203-208.

11. Ng, C. K., Shariat, S. F., Lucas, S. M., Bagrodia, A., Lotan, Y., Scherr, D. S., \& Raman, J. D. (2011, January). Does the presence of hydronephrosis on preoperative axial CT imaging predict worse outcomes for patients undergoing nephroureterectomy for upper-tract urothelial carcinoma?. In Urologic Oncology: Seminars and Original Investigations. Elsevier, 29(1), 27-32. 